\title{
Detection and typing of human papillomavirus using the Vira Type "in situ" kit: comparison with a conventional dot blot technique
}

\author{
B E Faulkner-Jones, V M Bellomarino, A J Borg, K Orzeszko, S M Garland
}

\begin{abstract}
A new commercial kit (Vira Type "in situ", Life Technologies, Inc., Molecular Diagnostics Division, Guithersburg, Maryland, USA) for the detection of human papillomavirus (HPV) types 6, $11,16,18,31,33$ and 35 in routinely processed human anogenital tissue was compared with a conventional dot blot assay for HPV 6, 11, 16 and 18. Both systems use double-stranded genomic DNA probes for the detection of type specific HPV DNA. The probes used on the dot blots were labelled with ${ }^{32} P$ and visualised autoradiographically. The Vira Type probes were labelled with biotin and visualised using a streptavidin-alkaline phosphatase conjugate with NBT-BCIP substrate. Biopsy specimens from the cervix, vagina, and vulva of 46 women were processed by both methods and compared. The histological diagnoses ranged from benign changes, to dysplasia, and invasive carcinoma. Overall, $50 \%$ of biopsy specimens were positive for HPV DNA by dot blot hybridisation; only $39 \%$ were positive by Vira Type in situ hybridisation. Three of the specimens positive by the Vira Type "in situ" kit showed no cross hybridisation and were the same HPV type as the dot blot. A further 13 showed cross hybridisation, but the strongest Vira Type result corresponded to the dot blot results. One biopsy specimen was positive for different HPV types by the two tests and one was positive by Vira Type and negative by dot blot. Six biopsy specimens were negative by Vira Type but positive by dot blot.
\end{abstract}

It is concluded that the Vira Type "in situ" kit has a similar specificity but lower sensitivity than the dot blot hybridisation method for the detection of HPV DNA.

Microbiology and Anatomical Pathology Departments, The Royal Women's Hospital, 132 Grattan Street, Carlton, Victoria, Australia, 3053

B E Faulkner-Jones V M Bellomarino A J Borg K Orzeszko

S M Garland

Correspondence to: Dr B E Faulkner-Jones Accepted for publication 11 June 1990 ome of about 8000 base pairs. HPV cannot be cultivated in vitro, and serological tests remain insensitive and relatively non-specific. the thickness of an infected and condylomatous epithelium, but virion production and cytopathic effect are limited to the upper and terminally differentiated layers. Histology and immunohistochemistry for capsid antigens are, in practice, relatively insensitive. Moreover, HPV produce the same cytopathic effect regardless of type. Nucleic acid hybridisation techniques remain the most sensitive way of detecting infection, and the only reliable way of typing the HPV involved. ${ }^{12}$

Over 60 types of HPV have now been identified and they exhibit tropism for different epithelia. The anogenital area is consistently infected by types $6,11,16,18,31,33$ and 35 , together with other less common types, such as HPV 42. It has become clear that types 6 and 11 are most often found in classic condylomata acuminata and subclinical "flat warts," or in low grade dysplasias. In contrast, high grade dysplastic lesions and invasive carcinomas are much more likely to be infected with HPV 16, 18, 31, 33 and 35. These HPV types can also be found in low grade lesions. ${ }^{3}$ In condylomatous lesions HPV generally exist as free intranuclear episomes, but in genital carcinomas and some dysplasias they are integrated into the host cell genome.

Controversy still exists about the frequency with which low grade dysplasias progress to high grade dysplasia and to invasive carcinomas, but progression does occur in a proportion of patients. ${ }^{4}$ Strong epidemiological and in vitro evidence suggests that lesions infected with HPV 16, 18, 31, 33 and 35 have a higher risk of progression to invasive carcinoma than types $6,11 .^{56} \mathrm{~A}$ direct aetiological role for these HPV in malignant transformation, however, is yet to be proved. It has been suggested that the detection and typing of HPV in anogenital lesions may help to predict the clinical course of lesions, thereby allowing the allocation of screening and treatment programmes to be planned effectively.

\section{Methods}

The study group comprised 46 women referred between February 1987 and July 1988 to the Dysplasia Clinic of the Royal Women's Hospital, Melbourne, because of an abnormal cervical smear. Colposcopically directed target biopsy specimens were taken and bisected; failing that, adjacent target biopsy specimens were taken. One sample was sent for HPV DNA detection and the other for routine histological analysis. The viral genome can be found throughout
HPV DNA DETECTION BY DOT BLOT HYBRIDISATION

Briefly, DNA was extracted with phenol- 
chloroform after initial proteinase $\mathrm{K}$ digestion and then precipitated with ethanol. ${ }^{7}$ Quantitation was performed by comparison with lambda phage (Hind III) DNA markers after gel electrophoresis. Duplicate samples of $3 \mu \mathrm{g}$ of DNA were dotted on to nylon membranes (Zeta Probe, Bio Rad) using a 96-well vacuum manifold (Biodot apparatus, Bio Rad) and baked for 30 minutes at $80^{\circ} \mathrm{C}$ (instruction manual for DNA dot blotting, Bio-Rad). Genomic HPV DNA probes cloned into plasmid pBR322 (HPV 6, 11, and 16 into the Bam H1 site and HPV 18 into the Eco $R 1$ site) were kindly supplied by Professor Harald zur Hausen, Heidelberg, West Germany. Plasmids were transformed into Escherichia coli HB 101 and then isolated by caesium chloride ethidium bromide gradient ultracentrifugation. HPV insert DNA was recovered using the appropriate restriction enzyme and purified by agarose gel electrophoresis. Inserts were labelled using ${ }^{32} \mathrm{P}$ dATP (Amersham UK) either by oligolabelling or by using the Multiprime DNA labelling kit (Amersham) to a specific activity of $2-6 \times 10^{8} \mathrm{cpm} / \mu \mathrm{g}$ of DNA. ${ }^{8}$

One of the pair of filters produced for each patient was hybridised with combined HPV $16 / 18$ probes and the other with pBR322 DNA. Hybridisation was performed using 12-14 ng of radiolabelled probe $/ \mathrm{ml}$ at high stringency $\left(\mathrm{Tm}-20^{\circ} \mathrm{C}\right.$ ) for 22 hours. Filters were washed once in $2 \times \mathrm{SSC}$ at room temperature for seven minutes, once in $2 \times$ SSC $(0 \cdot 15 \mathrm{M}$ sodium chloride, $0 \cdot 15 \mathrm{M}$ sodium citrate), $0 \cdot 1 \%$ sodium dodecyl sulphate (SDS) at room temperature for 15 minutes and three times at $65^{\circ} \mathrm{C}$ for one hour in $0.1 \times \mathrm{SSC}$ and $0.1 \% \mathrm{SDS}$. The filters were left to autoradiograph for one to five days at $-70^{\circ} \mathrm{C}$ with Kodak XAR-5 film and two intensifying screens. Both filters were then stripped of probe and one rehybridised with combined HPV 6/11 DNA and the other with pBR322 DNA, using the same conditions.

HPV DNA DETECTION USING VIRA TYPE KIT Specimens sent for routine histological analysis were used for in situ hybridisation. Control sections, prepared from cell blocks of HeLa, $\mathrm{CaSki}$, and SiHa cell lines, were also used. Tissue processing, pretreatments, hybridisation and detection were carried out according to the manufacturer's instructions with some minor modifications. Briefly, the procedure was as follows. Tissue was fixed in $10 \%$ buffered formol-saline for a variable period, paraffin wax embedded, and then cut at 4-5 $\mu \mathrm{m}$. Seven sections per case were floated on to silanated slides, air dried and then baked for at least 30 minutes at $58^{\circ} \mathrm{C}$ before dewaxing through xylene and dehydrating in absolute ethanol. A protease/hydrochloric acid digestion step was followed by a TRIS-buffered saline wash and dehydration through graded ethanols. Forty to 80 microlitres of hybridisation buffer containing biotinylated HPV DNA probes were added to each of the sections as follows: the first was probed with combined HPV 6/11, the second with HPV 16/18, and the third with HPV 31/ $33 / 35$. One positive and one negative control probe (human placental DNA and pBR322
DNA, respectively) were included each time and the remaining two sections were stained with haematoxylin and eosin for histological assessement.

Coverslips were carefully applied to exclude all air bubbles and the slides were then heated at $95^{\circ} \mathrm{C}$ for 15 minutes. Hybridisation was carried out for two hours at $37^{\circ} \mathrm{C}$ in a humidified chamber. Coverslips were removed by gentle agitation in TRIS-buffered saline with bovine serum albumin and three post-hybridisation washes performed using the same buffer at $37^{\circ} \mathrm{C}$. Forty to 80 microlitres of streptavidinalkaline phosphatase conjugate were added to the sections which were then incubated for 20 minutes at $37^{\circ} \mathrm{C}$ in a humidified chamber. The slides were washed with TRIS-buffered saline and then immersed in nitroblue tetrazolium chloride (NBT)-5-bromo-4-chloro 3indolylphosphate p-toluidine salt (BCIP) substrate in TRIS-saline buffer for one hour at $37^{\circ} \mathrm{C}$. The reaction was terminated by washing in distilled water and sections were then counterstained with nuclear Fast Red for 15 minutes. Sections were washed again with water, dehydrated through ethanols, cleared in xylene then mounted in DEPX (Gurr, BDH chemicals). The whole procedure, from sectioning to histological assessment, can be performed during a normal working day.

\section{Results}

Overall, $50 \%$ (23/46) of biopsy specimens were positive for HPV DNA by dot blot, with seven positive for HPV types 6 and 11 and 16 positive for HPV types 16 and 18. The detection limit for the dot blot assay was taken as $12.5 \mathrm{pg}$ of HPV DNA. The correlation of HPV type with histology is given in table 1 .

Vira Type "in situ" detected HPV DNA in $39 \%(18 / 46)$ of specimens, with six positive for types 6 and 11 and 12 positive for HPV types 16 and 18 (figs 1 and 2). The correlation with histology is shown in table 2 . Twenty two biopsy specimens were negative by both assays. In three cases positive for HPV DNA the Vira Type and dot blot result agreed and there was no cross hybridisation with Vira Type results. A further 13 cases showed cross hybridisation with the Vira Type test (fig 2D). As suggested by the manufacturers, if a signal was evident in more than one probe group, the strongest signal was taken to represent the viral type, and in these 13 cases this agreed with the dot blot result. One biopsy specimen was positive for HPV DNA by both assays but for different types and one biopsy specimen was positive for HPV DNA by Vira Type "in situ" hybridisation but negative by dot blot. Six biopsy specimens were positive by dot blot but negative by Vira Type "in situ" hybridisation. The correlation between dot blot and Vira Type results is given in table 3.

Positive signals were obtained using Vira Type "in situ" for the CaSki and HeLa cell lines (500-600 copies of HPV 16 and 10-50 copies of HPV 18, respectively), but the signal in HeLa cells was very weak. No signal was obtained for the SiHa cell line (one copy of HPV 16). 
Table 1 Correlation of HPV types by dot blot hybridisation with histological assessment of cervical biopsy specimens

\begin{tabular}{|c|c|c|c|c|c|c|c|}
\hline \multirow[b]{2}{*}{ HPV DNA type } & \multicolumn{7}{|c|}{ Histology } \\
\hline & Normal & $\begin{array}{l}H P V \\
\text { infection }\end{array}$ & CIN I & CIN II & CIN III & $\begin{array}{l}\text { Invasive } \\
\text { squamous } \\
\text { carcinoma }\end{array}$ & Total \\
\hline HPV $6 / 11$ & 1 & 4 & 1 & - & - & 1 -vulva & 7 \\
\hline HPV $16 / 18$ & - & 4 & - & 2 & 9 & 1-cervix & 16 \\
\hline Negative & 14 & 5 & 2 & 1 & 1 & - & 23 \\
\hline Totals & 15 & 13 & 3 & 3 & 10 & 2 & 46 \\
\hline
\end{tabular}

Figure 1

Photomicrograph of a typical vulval condyloma acuminatum. (A) Section showing a koilocytosis

(haematoxylin and eosin).

(B) Lower magnification showing a positive signal with a combined HPV 6 |

$11 \mathrm{DNA}$ probe: the signal is strongest in the upper layers of the epithelium (alkaline phosphataseNBT-BCIP and nuclear Fast Red counterstain).

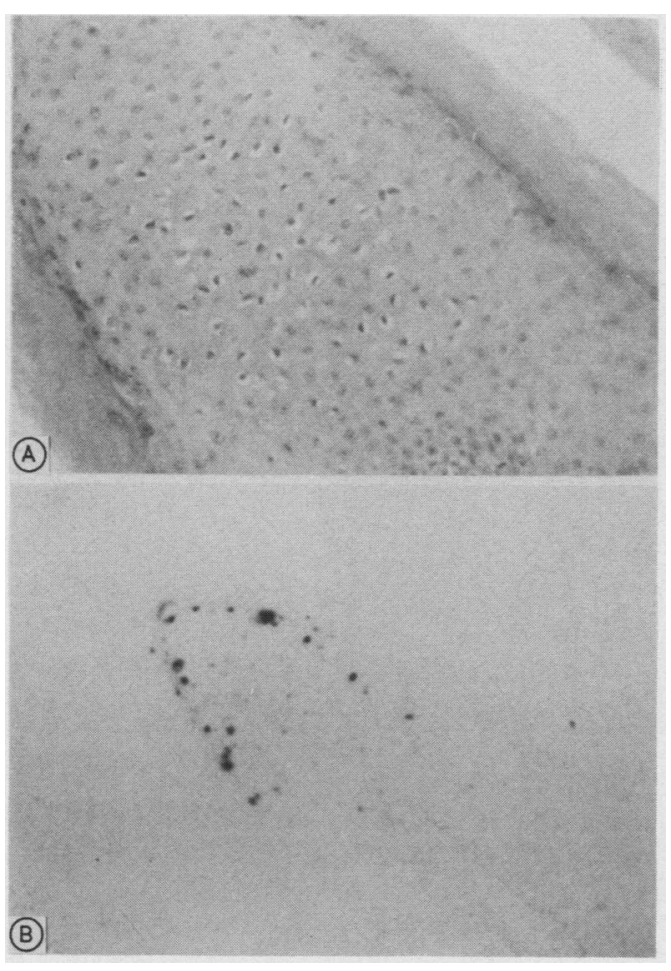

\section{Discussion}

Typing of papillomaviruses on routine anogenital biopsy specimens can be performed within one working day using the Vira Type "in situ" kit. While generally well designed and userfriendly, there was some scope for minor improvements to the kit. The manufacturers recommend that tissue be left in fixative for no more than 24 hours. Unfortunately this does not always occur in practice and may contribute to the lowered sensitivity of the kit relative to the dot blot method. Additionally, as emphasised by the manufacturers, sections cut on a dirty water bath increased the number of background hybridisation signals, especially from bacteria in the water. Heating sections on to silanated slides overnight at $60^{\circ} \mathrm{C}$, instead of 30 minutes at $58^{\circ} \mathrm{C}$, produced fewer lost sec- tions and no appreciable reduction in signal strength.

It was suggested to mark around the section with a diamond pen to aid visualisation during the procedure, but this sometimes resulted in broken slides after denaturation at $100^{\circ} \mathrm{C}$. An alcohol/xylene insoluble felt pen was found to be preferable. Although denaturing the section and probe DNA at $100^{\circ} \mathrm{C}$ on a heating block, several coverslips were forcibly dislodged by the hybridisation buffer boiling beneath them with obvious danger to the operator. Reducing the temperature from $100^{\circ} \mathrm{C}$ to $95^{\circ} \mathrm{C}$ in a hybridisation chamber and extending the time from five to 15 minutes avoided this danger and produced an adequate signal with improved morphological detail and fewer lost sections. The other small modification which was found to be useful was to increase the nuclear Fast Red counterstaining time from five to 15 minutes.

Signals were strongest in the upper layers of the epithelium and a strong signal provided no problems with interpretation. Some tissue sections, however, showed non-specific peripheral staining which could easily mask a weak signal. If more than one probe group produced a positive signal, the strongest signal was taken to represent the viral type and the others cross hybridisation. A true mixed infection, however, would be hard to interpret with this system. The hybridisation conditions used by the kit are effectively of medium stringency, and cross hybridisation between HPV groups is inevitable. An alternative strategy would be to screen at low stringency for all genital HPV to increase the sensitivity of the test, and then to type at high stringency to improve the specificity. This is already used by Life Technologies Inc. in their Vira-Pap Vira-Type kits for the detection and typing of HPV in cervical scrapes by dot blot.

The finding of two discrepant results could be a consequence of analysing different, albeit adjacent, specimens which harbour different HPV types. Additional HPV probes in the Vira

Table 2 Correlation of HPV type by Vira Type "in situ" hybridisation with histological assessment of cervical biopsy specimens

\begin{tabular}{|c|c|c|c|c|c|c|c|}
\hline \multirow[b]{2}{*}{ HPV DNA type } & \multicolumn{7}{|c|}{ Histology } \\
\hline & Normal & $\begin{array}{l}H P V \\
\text { infection }\end{array}$ & CIN I & CIN II & CIN III & $\begin{array}{l}\text { Invasive } \\
\text { squamous } \\
\text { carcinoma }\end{array}$ & Total \\
\hline HPV $6 / 11$ & - & 4 & 1 & - & - & 1 -vulva & 6 \\
\hline $\begin{array}{l}\text { HPV 16/18 } \\
\left({ }^{\star} \mathrm{HPV} 31 / 33 / 55\right)\end{array}$ & - & 2 & - & 3 & 7 & - & 12 \\
\hline Negative & 15 & 7 & 2 & - & 3 & 1-cervix & 28 \\
\hline Total & 15 & 13 & 3 & 3 & 10 & 2 & 26 \\
\hline
\end{tabular}

*All biopsy specimens showing a positive signal with the HPV $31 / 33 / 35$ group were strongly positive for HPV $16 / 18$ and the result read as HPV $16 / 18$ positive with cross hybridisation. 
Figure 2

Photomicrograph of vulval intraepithelial neoplasia (VIN) grade III. This patient previously had a superficially invasive squamous carcinoma of the vulva. (A) VIN III (haematoxylin and eosin). (B) Same area as figure $2 A$ showing a strong positive signal with a combined HPV 16/18 DNA probe. The signal is strongest in the upper layers of the epithelium, but positive nuclei can be seen towards the basal layer (alkaline phosphatase-NBTBCIP). (C) High power view of figure $2 B$ to show intranuclear localisation of $H P V 16 / 18 D N A$. (D) VIN III showing a weak positive signal with combined HPV 31/33/35 DNA probe. This weak signal was taken to represent cross hybridisation between HPV, most likely between $H P V 16$ and HPV 31 in this case. (This biopsy specimen was typed as HPV 16/18 positive).

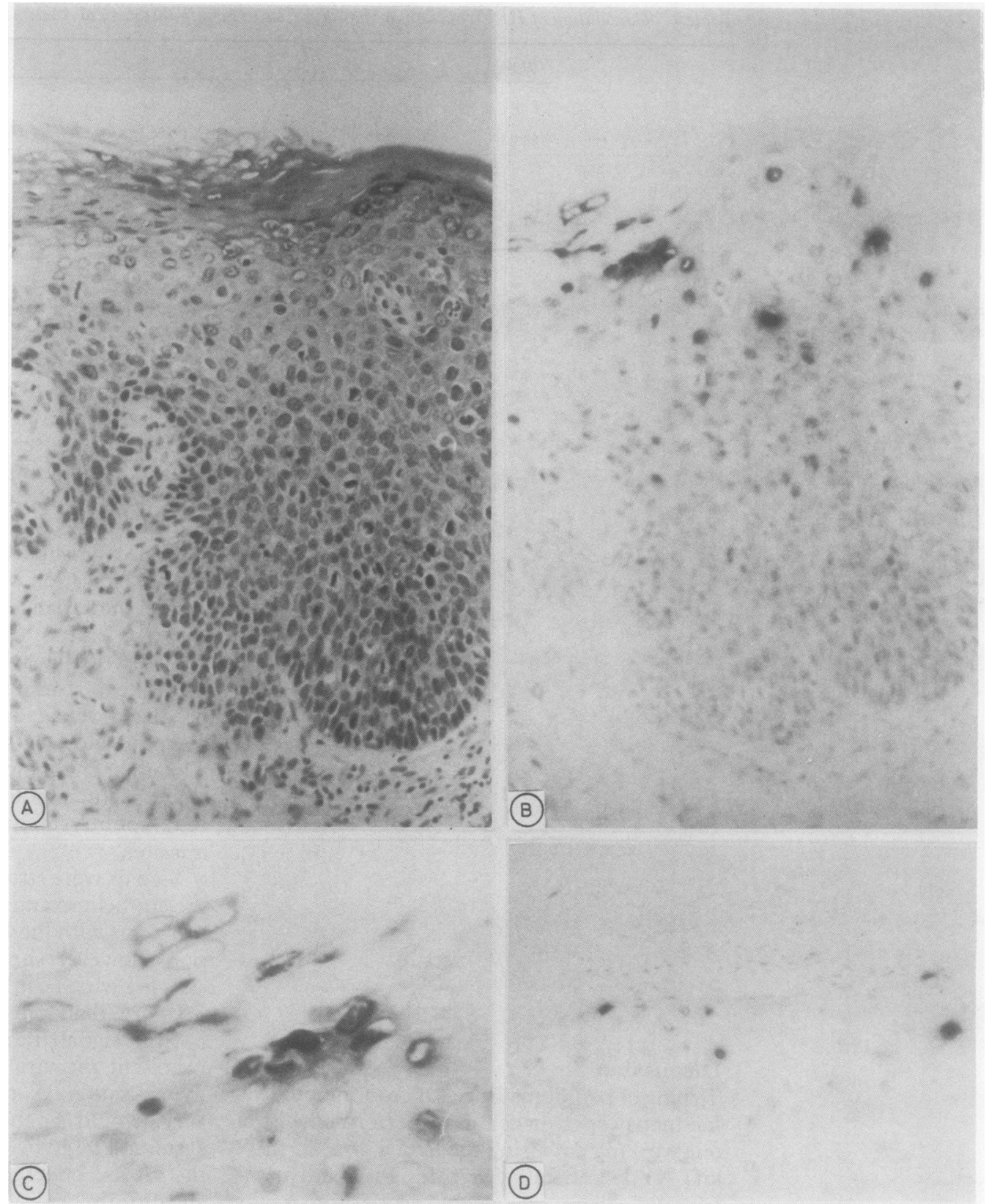

The Vira Type kit, although less sensitive than the dot blot assay, does have the advantage of not requiring special expertise or equipment. In addition, archival tissue can be used for retrospective studies and the lesion associated with the HPV infection can be assessed.

Currently, management of CIN depends on clinical and histological assessment of individual women and HPV typing is therefore largely of academic interest. If, however, the association between certain HPV types and

Table 3 Correlation of Vira Type "in situ" hybridisation result with dot blot result and histological assessment of cervical biopsy specimens

\begin{tabular}{|c|c|c|c|c|c|c|c|c|}
\hline \multirow{2}{*}{$\begin{array}{l}\text { Vira type } \\
\text { "in situ" } \\
\text { hybridisation } \\
\text { and dot blot } \\
\text { results }\end{array}$} & \multirow[b]{2}{*}{$H P V D N A$} & \multicolumn{7}{|c|}{ Histology } \\
\hline & & Normal & $H P V$ & CIN I & CIN II & CIN III & $\begin{array}{l}\text { Invasive } \\
\text { squamous } \\
\text { carcinoma }\end{array}$ & Total \\
\hline \multirow{8}{*}{$\begin{array}{l}\text { Negative by both assays } \\
\text { Positive by both assays, no cross hybridisation } \\
\text { Positive by both assays, cross hybridisation } \\
\text { with Vira Type } \\
\text { Positive by both assays- } \\
\text { different HPV types } \\
\text { Negative by dot blot, positive by Vira Type HPV } \\
16 / 18 / 31 / 33 / 35 \\
\text { Positive by dot blot, } \\
\text { negative by Vira Type }\end{array}$} & Negative & 14 & 5 & 2 & - & 1 & - & 22 \\
\hline & $6 / 11$ & - & 2 & 1 & - & - & - & 3 \\
\hline & $6 / 11$ & - & 1 & - & - & - & 1-vulva & 2 \\
\hline & $16 / 18$ & - & 2 & - & 2 & 7 & - & 11 \\
\hline & $\begin{array}{l}\text { HPV } 6 / 11 \text { by Vira Type } \\
\text { HPV } 16 / 18 \text { by dot blot }\end{array}$ & - & 1 & - & - & - & - & 1 \\
\hline & & - & - & - & 1 & - & - & 1 \\
\hline & HPV 6/11 & 1 & 1 & - & - & - & - & 2 \\
\hline & HPV $16 / 18$ & $\overline{15}$ & 1 & $\overline{3}$ & $-\overline{3}$ & 2 & 1-cervix & 4 \\
\hline
\end{tabular}


carcinogenesis becomes more clearly established, HPV typing could have a role in the management of CIN. In order to assess this association more data from prospective follow up trials (with normal control groups) needs to be obtained, with analysis of HPV types, the lesions involved, and progression or regression rates. The Vira Type "in situ" kit would allow routine pathology laboratories to type HPV in biopsy material and provide some of these data.

We thank John Howlett, marketing manager, Gibco-BRL, Australia, and Dr Rosemary Versteegen of Life Technologies Inc., Molecular Diagnostics Division, USA, for kindly providing us with the Vira Type "in situ" kits; Mr W Chanen and the staff of the Dysplasia Clinic, Royal Women's Hospital, for providing the clinical specimens; and Mrs Judy Jackson and Miss Voula Polites for typing the manuscript.
1 Pfister H. Biology \& biochemistry of papillomaviruses. Rev Physiol Biochem Pharmacol 1984;99:111-81.

2 Lorincz AT. Detection of human papillomavirus infection by nucleic acid hybridisation. In: Reid R, ed. Human

3 papillomavirus. Philadelphia: WB Saunders, 1987:451-69. roker TR. Structure and genetic expression of papilloma-
viruses. In: Reid R, ed. Human Papillomavirus. Obstetric viruses. In: Reid R, ed. Human Papillomavirus. Obstetric
$\mathcal{E}$ Gynecology Clinics of North America. Philadelphia: WB

4 McIndoe WA, McLean MR, Jones RW, Mullins PR. The invasive potential of carcinoma in situ of the cervix. Obstet Gynaecol 1984;64:451-8.

5 McCance DJ. News on papillomaviruses. Nature 1988;335:765-6.

6 Syrjanen K, Mantyjarvi R, Varynen M, Syrjanen S, et al. Evolution of human papillomavirus infections in the uterine cervix during a long-term prospective follow-up. Appl Pathol 1987;5:121-35.

7 Appendix A: Biochemical Techniques. In: Maniatis T, Fritsch EF, Sambrook J. Molecular cloning: A laboratory manual. New York: Cold Spring Harbour Publications, manual. New

8 Feinberg AP, Vogelstein B. A technique for Radiolabelling DNA restriction endonuclease fragments to high specific activity. Anal Biochem 1983;132:6-113. 